\title{
AC 2010-24: A VIRTUAL FACTORY APPROACH FOR DESIGN AND IMPLEMENTATION OF AGILE MANUFACTURING SYSTEMS
}

\section{Hamed Farahani Manesh, Eastern Mediterranean University}

Hamed F. Manesh received his PhD degree in Mechanical Engineering from the Eastern Mediterranean University, N. Cyprus. He was a Research Assistant and Lecturer in this university from 2003 to 2010. He received his first Master's Degree in Information Systems and the second in Mechanical Engineering also from Eastern Mediterranean University. Currently, he is involved in a research group, which carries out research and development activities for industry-oriented projects of intelligent manufacturing systems, automation, virtual manufacturing as well as engineering education. He has authored and co-authored various journal and conference publications. His research interests include: virtual reality, CAD/CAM, Multi-agent based manufacturing systems control and automation, robotics, holonic manufacturing systems, agile manufacturing and wireless sensor networks.

\section{Dirk Schaefer, Georgia Institute of Technology}

Dr. Dirk Schaefer is an Assistant Professor in the Woodruff School of Mechanical Engineering at the Georgia Institute of Technology. Over the past ten years, Dr. Schaefer has been conducting research in the interface domain between Engineering, Computer Science, and Information Technology principles in Germany, the United Kingdom, and the United States. Long standing work has addressed product modeling, variant design, product life-cycle management, interdisciplinary ECAD-to-MCAD integration, design-with-manufacture integration, standardized product data exchange, knowledge management as well as virtual engineering, digital enterprise technology and systems integration.

Dr. Schaefer's current research is focused on the Scholarship of Integration and the Scholarship of Education. His contributions to the Scholarship of Integration concern the highly topical area of Designing Mechatronic Systems. In his research, Dr. Schaefer addresses questions related to the integration of design domains, domain-specific CAD and CAE systems, interfaces for standardized data exchange between domain-specific PDM systems, and automated variant design generation of mechatronic systems and system families. Dr. Schaefer's contributions to the Scholarship of Education concern one of the 14 Grand Challenges for Engineering as stated by the National Academy of Engineering - "Advance personalized learning." In his research, Dr. Schaefer addresses the strategic design of engineering education for the next generation of engineers, the integration of game-changing paradigms such as mass customization, personalization and collaborative learning into the engineering curriculum, as well as virtual learning environments and remotely/robotically controlled physical laboratory exercises for distance learning settings including associated pedagogies.

Dr. Schaefer has published approximately 80 papers in journals, books and conference proceedings on Computer-Aided Engineering and Design as well as Engineering Education. In addition, he has substantial experience in curriculum development, ABET preparation and assessment. 


\title{
A Virtual Factory Approach for Design and Implementation of Agile Manufacturing Systems
}

\begin{abstract}
Worldwide competition among manufacturing enterprises has acted as a driving force for the design, development and utilization of manufacturing systems with an increased degree of agility. In these regards, Holonic Manufacturing Systems (HMS) are considered an intelligent systems paradigm to meet requirements for agile manufacturing systems. Despite all advantages of HMS, design and implementation of such control systems for real industrial cases is time consuming and requires risky, but careful consideration. While some universities may be able to expose their students to the latest manufacturing systems and technologies, others may not be that fortunate due to the lack of financial resources. Because of this, alternative ways for providing their students with equivalent education and training need to be developed. A potential solution for this issue is the adoption of advanced computer technology to facilitate the provision of flexible manufacturing-related education and training programs. To date, many studies have shown that the use of computers for teaching and training purposes is feasible and rapidly becoming an integral part of the general learning process. This paper presents a Virtual Reality (VR) system tool "VR-HMS" developed for training on design of holonic manufacturing control systems to enhance the development process. The proposed VR system is a safe approach to teaching the operations of HMS, which is well known as a large-scale and complex systems for a number of operational and structural reasons. The VR-HMS allows trainees to self-experience on these systems without the need to work in actual industry.
\end{abstract}

\section{Introduction}

A side-effect of continuing globalization is that manufacturing is more and more becoming a commodity. In addition, the manufacturing industry has to respond to rapidly changing markets more often and much faster than ever before. The ability to respond to change, predicted or unpredicted, is referred to as agility and the associated industrial paradigm called agile manufacturing. A key goal is to make the manufacturing equipment, associated information systems and control architecture of an agile manufacturing enterprise as responsive to the physical and logical disturbances as possible [1].

Several technologies have been developed to implement agility within manufacturing enterprises, including Flexible Manufacturing Systems (FMS) and Computer Integrated Manufacturing (CIM) systems. Such systems consist of flexible, programmable manufacturing hardware and information system components. They allow for centralized control of manufacturing-related activities and help to improve the overall integration of design with manufacturing. In addition, they may support production planning and scheduling, enhance product service activities such as maintenance and repair, and furthermore provide a vehicle for manufacturing training and research [2]. 
However, traditional centralized control architectures were not designed to cope with different types of information, expertise and decision-making as is common in today's increasingly competitive global market [3]. Due to the centralized control, many conventional CIM systems suffer from the limitations of scalability, robustness and re-configurability, which are the key parameters of an agile enterprise.

One widely accepted approach in response to the above challenges is the introduction and utilization of so-called Holonic Manufacturing Systems (HMS). To date, there have been many studies on HMS development. Most of those conducted are based on a generic shop floor control system with a main focus to the model definition or to a specific description of algorithm at a theoretical state [4]. In terms of the experimental research, HMS developments are typically conducted on "toy simulation cases". As a consequence, many researchers are refrained from problems and uncertainties that a real shop floor could impose [4, 5]. Furthermore, HMS possesses non-deterministic behavior. Hence, testing HMS in a real manufacturing environment is costly and requires several experiments in order to predict the behavior of the system [6].

Taking all into account, the design and implementation of such a highly complex control system is costly, time consuming, and requires a lot of experience to mitigate potential risks of failure. Therefore, new methods and tools for designing manufacturing systems with intelligent control architectures, such as HMS, in a quick, cost-effective manner that is error and risk free, which are needed by the industry.

While there are a number of simulation methods and commercial tools available for design and development of integrated manufacturing systems, most of the state-of-the-art manufacturing simulation tools do not contain built-in capabilities and functions regarding negotiation and selforganization. Overall, applications that are capable of simulating the de-centralized control of manufacturing systems are very limited. It still is a challenge to build a system which is able to provide an efficient and effective means to design and develop manufacturing systems with modular, interactive elements that, in addition, facilitate a de-centralized, intelligent manufacturing control architecture into the manufacturing simulation in order to allow for the design of an agile factory.

In light of this, the authors address the issue of how engineering students and practicing engineers can be trained (safely and cost-effectively) in the design and implementation of Holonic Manufacturing Systems. Utilizing Virtual Reality (VR), an integrated methodology for design and operation of holonic agile manufacturing systems that only requires limited expertise and minimum cost has been proposed. The aim is to integrate so-called Virtual Factory (VF) simulation into the design process of modular and re-configurable manufacturing systems. The methodology utilizes two major components: 'VR-based simulation' and 'holonic manufacturing control' in an information system framework for design and operation of manufacturing systems.

A 3-D visualization platform provided through a VR-based simulation tool allows system designers to create any kind of common manufacturing operations. The underlying holonic control architecture is built upon a multi-agent system (MAS) of autonomous and cooperative decision making agents. The overall methodology has been implemented as an easy-to-use tool for manufacturing systems education. 
The remainder of this paper is organized as follows: Section 2 presents an overview of the characteristics and structure of HMSs. Section 3 covers relevant background information with regard to research in Virtual Environments (VEs) in Manufacturing Education. Section 4 outlines the realization of such a VE application that in addition utilizes Virtual Reality software ('VRHMS'), which has been developed to train engineering students in the design of Holonic Manufacturing Control Systems. Finally conclusions regarding the effectiveness of this approach are drawn in Section 5.

\section{Holonic Manufacturing Systems: An Overview}

Holonic Manufacturing Systems are Intelligent Manufacturing System (IMS) that integrate the entire range of manufacturing activities from order booking through design, production and marketing in order to realize a highly agile manufacturing enterprise. In production environments, the main advantages of HMSs are their distributed computational operations, their distributed decision making functions as well as the cooperation between intelligent entities characteristics that do not exist in conventional control systems [7].

HMSs are based on a combination of hierarchical and heterarchical control structures by means of cooperating holons [8]. The term holon, in the sense in which it is currently used in the manufacturing area, was introduced by A. Koestler [9]. He stated that - in principle - wholes and parts in the absolute sense do not exist anywhere. To emphasize this point, he suggested a new term 'holon' as a fusion of the Greek word 'holos' meaning the 'whole' and the suffix 'on' denoting a particle (as in neutron).

The most common implementation of HMSs is through Multi-Agent System (MAS) technology. MASs possess special features for modeling intelligent systems, such as autonomy, rationality, reactivity, pro-activeness, adaptability, mobility, and benevolence. They provide clear, unambiguous analysis and design guidelines for HMS modeling and development [10].

Many researchers have pointed out that holons and agents are very similar concepts $[11,12]$. However, some extensions must be considered in MAS methodology to model the HMS requirements in an appropriate way. These are: a 'holon recursive structure, system abstraction levels, and a mixed top-down and bottom-up approach for design and analysis process' [11]. Moreover, the availability of complete MAS methodologies makes such technology suitable for HMS modeling and implementation in such a way that holons and their interactions are modeled and simulated throughout the agents [10-13].

\section{Virtual Environment in Manufacturing Education}

In engineering education it is desirable for students and trainees to obtain a great deal of practice, which leads to a sound understanding of the subject matter. Unfortunately, this is not always possible due to lack of resources in terms of state-of-the-art equipment, laboratory space, personnel, and maintenance. One potential approach to improve experience-based education is through the utilization of so-called Virtual Environments (VEs). Simply put, a VE is a computer system, which generates a virtual 3-D environment within which users can interact and receive 
real-time feedback [14]. Studies have emphasized the great potential of VEs for educational purposes at all the levels. For example, Tan and Francis [15] showed that it is possible to use VEs as a training tool, especially in domains that use complex and potentially dangerous equipment.

In the manufacturing sector, simulation packages with three-dimensional modeling and animation capabilities are progressively gaining favor. The visualization capability provided by 3-D modeling and simulation packages not only provides much richer, closer-to-reality information for users, but also enables new application domains to be addressed, such as design and development models for rapid prototyping of machine systems, layout design, process planning [16], tele-robotics, assembly planning, manufacturing system visualization and simulation [17-20]. These applications have a significant role in bringing systems into operation more rapidly and more reliably because more testing and verification can be done earlier in the life cycle and in a safe environment.

A major outcome of the virtual environment research in manufacturing has lead to the development of Virtual Factories (VFs). A Virtual Factory can be defined as 'a complex computer based simulation system that provides the manufacturing system designer all the resources and tasks necessary to achieve the optimized operation of designing, producing and delivering a product' [21].

The utilization of VFs in manufacturing education has been emphasized by many researchers. It has been shown that people can indeed learn to perform certain tasks such as console operation from virtual environments and that knowledge and skills acquired through a VR simulation can be effectively applied in the real world [22].

\section{VR-Based Holonic Design and Operations Environment: The Overall Methodology}

The proposed approach exploits simulation in a much wider range of applications with significant benefits in the design and development of agile manufacturing systems. To this end, a number of integration mechanisms are facilitated in supporting processes in a typical design and development life cycle.

These include:

(i) Creating VR manufacturing environments based on functional and holonic control requirements.

(ii) Identification of holons and holarchies for modeling holonic control architectures by MASs in a wrapper model as shown in figure 1. Exchanging the control requirement/design information between VR simulation and the holonic operations environment. 
(iii) Performing distributed control of manufacturing devices and execution of control functions in VR operations environment with holonic architectures with runtime support application verification.

The overall methodology, as shown in Figure 1, is built upon design and integration of two major environments: (1) holonic control, and (2) VR operations environments. A common design platform based on object-oriented design and programming is employed for modeling the two environments and the interactions between them.

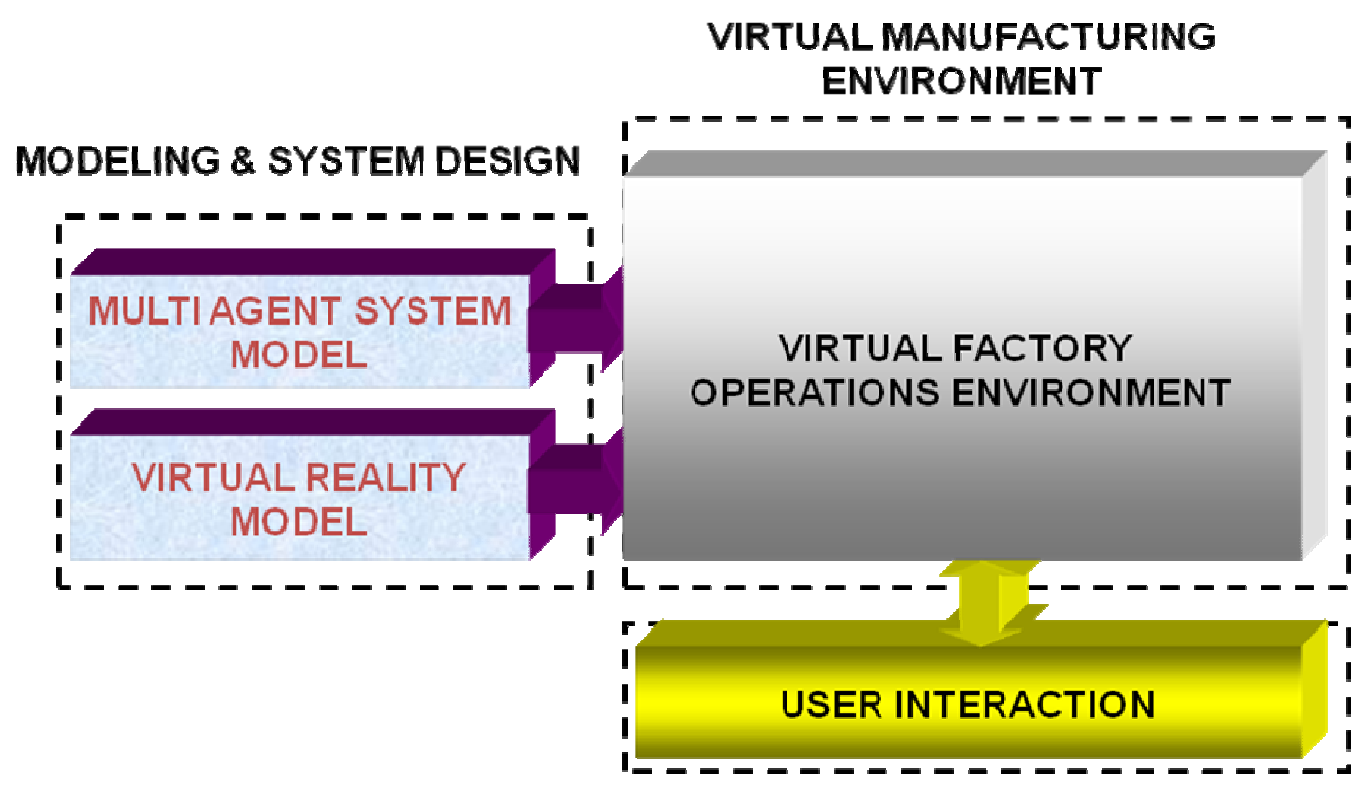

Figure 1: The Overall Methodology

\section{Design Environments}

The integrated design environments focus on building a 'Virtual Factory', based on two main types of models, namely: VR model and holonic control model (Fig. 2). The VR model represents the 3-D image of the manufacturing system for simulations in the virtual world. Various manufacturing and assembly operations may be simulated throughout movements and interactions of the 3-D graphical VR objects. DELMIA Quest [23] has been unutilized for the development and simulation of the virtual factory. The DELMIA package by Dassualt Systems provides an application platform for developing virtual manufacturing environments under consideration of process planning, cost estimation, factory layout, factory simulation and so on. In addition, the object-oriented modeling paradigm has been applied throughout the VF development. Hence, VR objects are constructed based on object-oriented structures. Interactions within the virtual world occur based on event and information flow between objects. The objectoriented approach of modeling is helpful also in the integration of VR environments to agentbased holonic control systems since the major structural components of HMSs are object- 
oriented MAS. The holonic control model involves agents and represents basic manufacturing and material handling components, including a manufacturing cell, a conveyor belt, an AGV, etc.

For the implementation of the proposed methodology, the JADE platform has been used due to its several advantages mentioned in [24]. Agents, as intelligent decision making components of VR environment objects, are designed in the JADE platform based on the FIPA interaction protocols. The JADE platform, which is an open source agent platform, provides a library of JAVA classes that allows for creating agents with application-specific attributes and behavior with capabilities to send and receive FIPA messages. A key characteristic of the agent platform is that it provides a 'runtime platform' for the agents to 'live'. This includes white page services registering existing agents and their contact addresses, yellow pages services used to register and locate services and finally the message dispatching mechanism ensuring the inter-agent communication within the platform as well as hosted by different platforms.

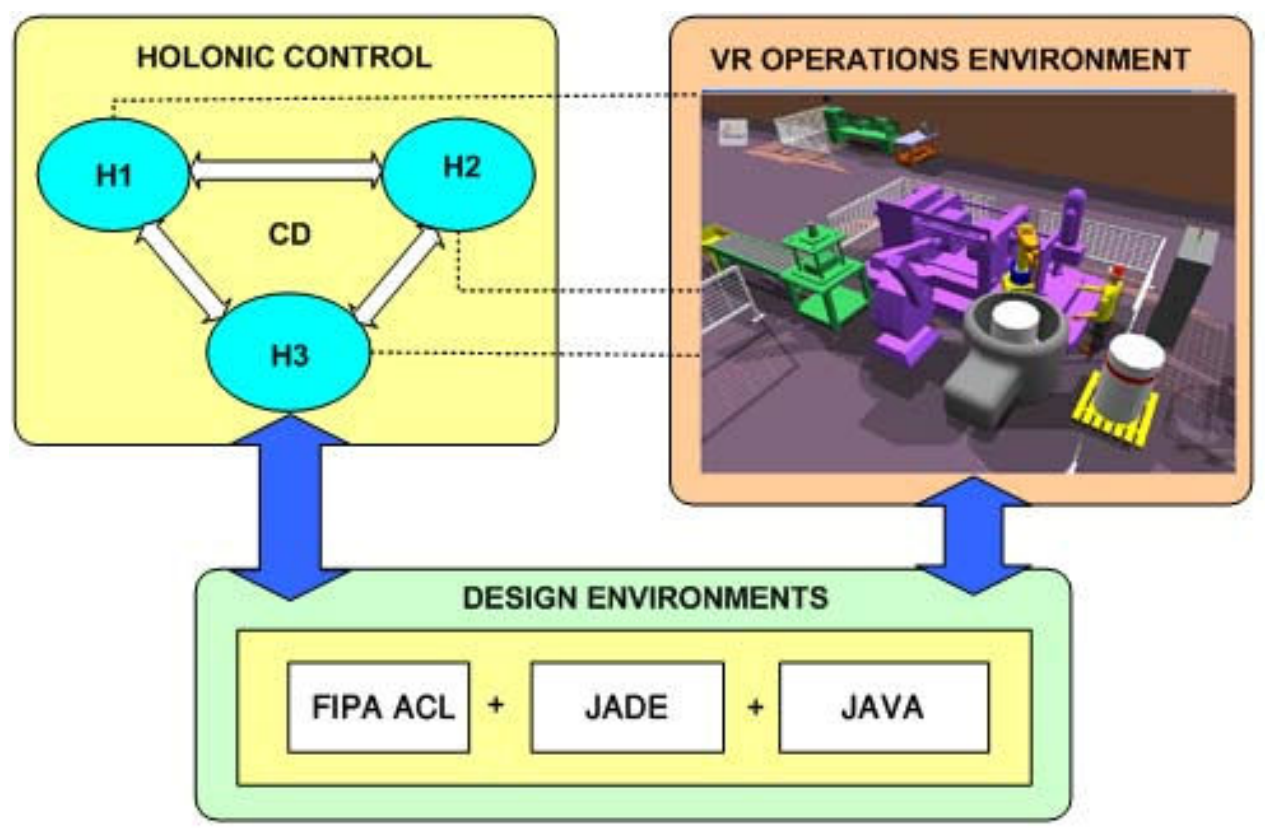

Figure 2: The VR-Based Holonic Design and Operations Environment

\section{VR Operations Environment}

The developed VR operations environment consists of an interactive VR container platform with a GUI for receiving user requests upon several manufacturing operations, editing parameters of production processes and viewing the HMS operations in virtual environment. The objects of the VR environment communicate with the holonic control agents' 'sockets', which are modular and re-configurable interfaces for data transfer between software platforms based.

The holon agents designed for the control of the virtual manufacturing system is directly connected to the VR objects in order to trigger the events of operations in VR environment. Each holon is autonomous and has the responsibility of maintaining its local knowledge and keeping its neighbor holons informed once something changed. None of the individual holons has the knowledge about the whole system. 
The VR operations environment constitutes a human system interface through which users may add or delete any type of system entities. Once a system entity is added to the system, a new holonic agent is automatically created and registered to the cooperation domain. The relationship between the new added holon with other holons (i.e. inputs and outputs relations) is updated in its knowledge base. Through the dynamic information exchange among holonic agents the transport network of the entire system is stored in each individual holon and any change of the system layout can be detected and captured. The integration of holonic agent control system with the VR simulations forms a design and operations environment for various HMS operations, i.e. material handling, assembly, manufacturing.

The human system interface of the platform is used to let user interactively change the system configuration and communicate with other holonic agents to adapt to the changing environment. In addition, the user can simulate several failures of system components and trace the reaction of holonic control for finding delivery routes, repairing workstations and dynamically updating the production schedules.

\section{Implementation of a 'Virtual Reality-Based Holonic Manufacturing System (VR-HMS)' in Agile Manufacturing Laboratory Education}

The VR-HMS module has been designed and developed for use as a visual demonstration and laboratory support tool for teaching various multidisciplinary topics related to agile manufacturing, including holonic manufacturing systems. The module has been used for teaching engineering students the theory and the operating principles of HMS and MAS through interactive demonstrations and the standalone experiments in the virtual environment.

The VR-HMS provides several distinguished combinations of laboratory models for a step bystep approach to learning the main topics of HMS, starting from the easiest and going through to the hardest case. Figure 3 shows the flow of operations in the instructional process of CIM laboratory education. Interactive tutorials have been prepared for each VF model to provide background information about shop floor equipment, theory and operating principles of equipment, etc. The tutorial also include interactive simulations for the "how to?' instructions of using the VR environment, using software interfaces, defining holons, creating agents, orders and so on. The sample graphical user interface of the resource holon editor is shown in Figure 4. From the GUI of VR-HMS, every student on his/her desktop is able to develop holonic control, programs and production plans for existing system. The students are able to make and learn from their mistakes without endangering themselves or the equipment. The 3-D GUI interface shown in Figure 5 illustrates the arbitrarily user designed system layouts in DELMIA-Quest where the user can feel free to add/delete any of the system.

The evaluation of learning for each experiment through VR-HMS module takes place in the forms of: (1) A laboratory report, in which the students are asked to report the performed experiment by the procedures followed, results obtained, analysis and conclusions. (2) A questionnaire, which involves the questions regarding the VR-HMS module in order to collect feedback and opinion about the bugs, usability and effectiveness of the software in students' learning on the studied topic. (3) A lab quiz, given to all the students in order to measure the overall understanding of the subject studied through the laboratory experiment. 
Figure 6 presents a summary of the VR-HMS software usability evaluation based on the questionnaires. Application-related questions are based on heuristics scales as defined in Ref. [25]. All the participants are students, who take 'Computer Integrated Manufacturing' and "Manufacturing Systems" courses. The questionnaire results were calculated and scored based on the SUMI method [26]. The average rating of answers given to the some of the specific questions is presented in Table 1.

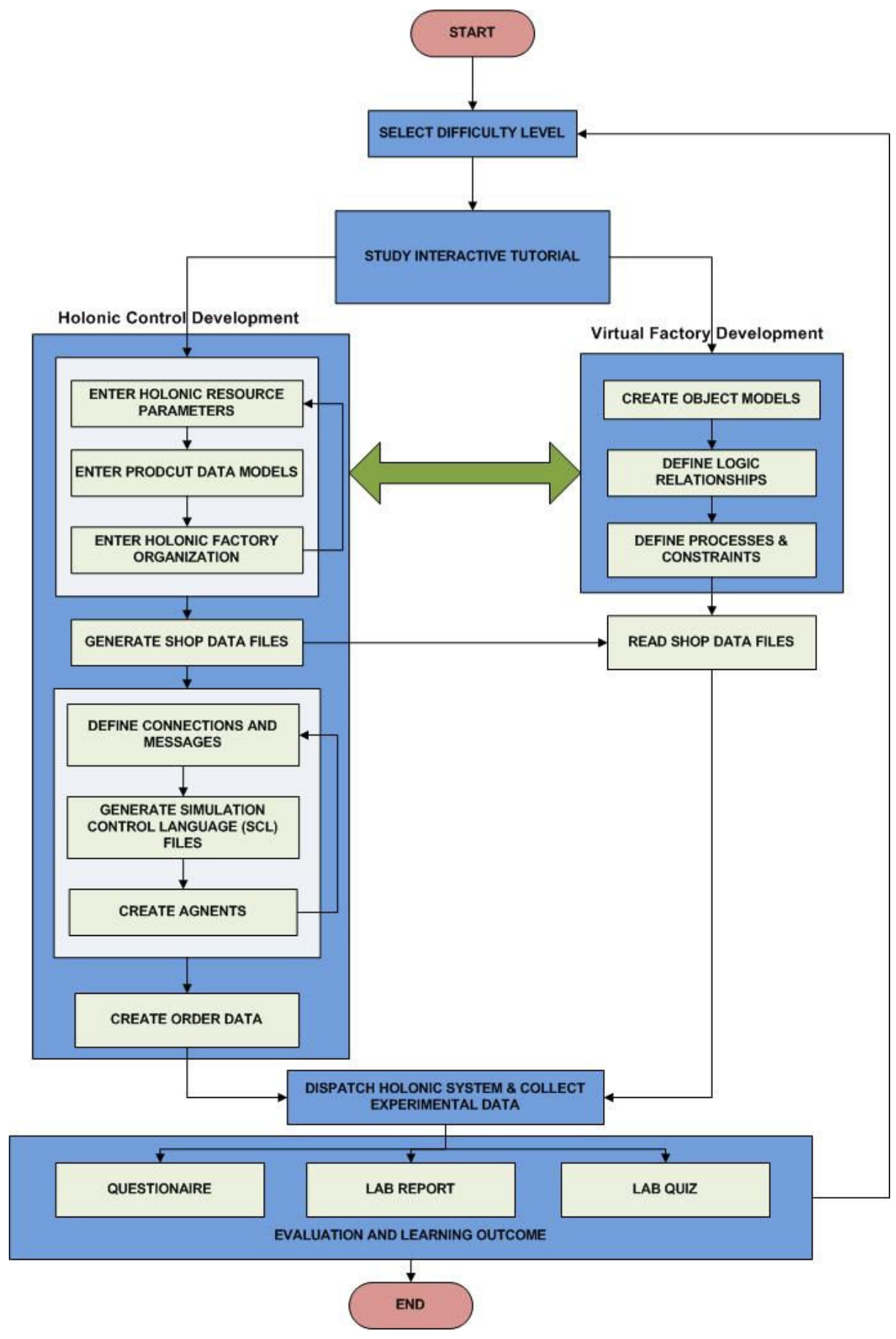

Figure 3: The flow of Operations in VR-HMS 


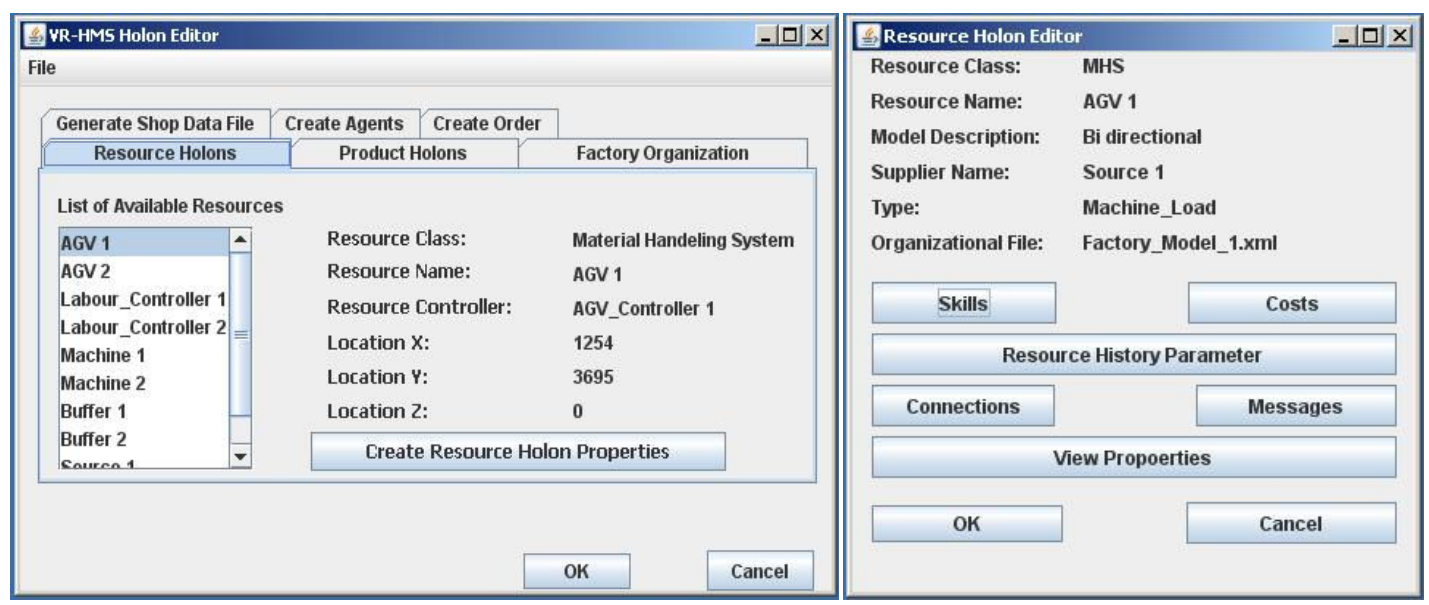

Figure 4: The Sample Graphical User Interface of the Resource Holon Editor

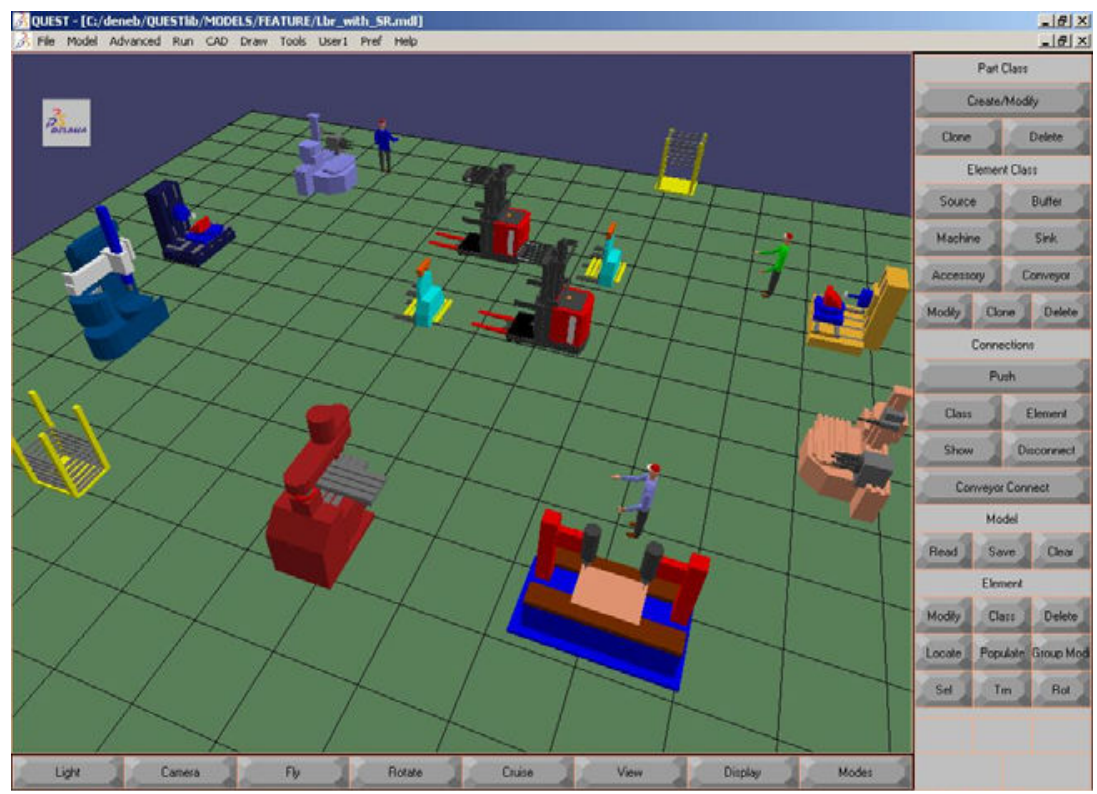

Figure 5: The User Designed System Layouts in DELMIA-Quest

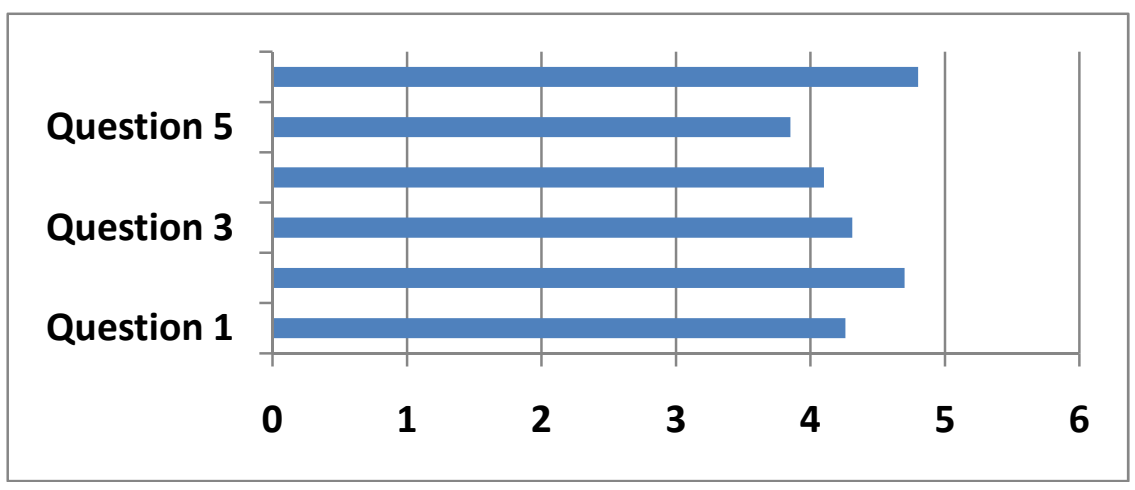

Figure 6: Evaluation of the VR-HMS Based on Heuristic Scales 


\begin{tabular}{|l|c|}
\hline Question & Overall Score (1-5) \\
\hline $\begin{array}{l}\text { VR-HMS was motivating for me to learn about Holonic } \\
\text { Manufacturing Systems. }\end{array}$ & 4.26 \\
\hline Virtual Reality helped me visualize the manufacturing process. & 4.70 \\
\hline $\begin{array}{l}\text { I was able to introduce new manufacturing tasks, design and } \\
\text { change the system layout though VR-HMS. }\end{array}$ & 4.10 \\
\hline $\begin{array}{l}\text { I was able to define a new holon into the system or modify the } \\
\text { existing holonic system in faster pace. }\end{array}$ & 3.85 \\
\hline $\begin{array}{l}\text { VR-HMS has sufficient visual level of detail to meet the lesson } \\
\text { objectives. }\end{array}$ & 4.80 \\
\hline $\begin{array}{l}\text { I was familiar with the concepts of the Agile Manufacturing } \\
\text { Systems after the performing experiments with VR-HMS. }\end{array}$ & \\
\hline
\end{tabular}

Table 1: Results of the selected questions from the VR-HMS questionnaires.

\section{Conclusions}

A VR-based methodology for design of holonic-agile manufacturing systems has been presented. The methodology uses VR for modeling, simulation and monitoring holonic manufacturing control systems and their operations. VR technology allows the students to interact intuitively with the manufacturing environments and its objects, as if they were real, by immersing them in a highly realistic 3-D environment.

As the earlier step of developing and implementing the VR-based holonic design and operations of agile manufacturing systems, the concept and technologies were validated; the original objective was achieved, thus, paving the way for further development and application. However, this is an on-going work and therefore only preliminary results are presented.

The developed system has been successfully used in the education and training of the Holonic manufacturing system as an agile manufacturing paradigm in the undergraduate and graduate courses of mechanical and industrial engineering departments at Eastern Mediterranean University (EMU) in Turkey. The training system makes use of computer simulations of various software components in order to provide a basic-to-advanced level training on the intelligent manufacturing systems.

According to our experience with the VR-based system developed in laboratory training, the following points have been found significant;

Students can realize the facts such as how holons (agents) are communication in a real manufacturing environment, including how to define messages, connections and so on.

The students can get things wrong safely without damaging machinery or work, this allows them to learn from their mistakes and develop their skills and understanding of the process.

In general, the VR - gives the system trainers or teachers the opportunity to introduce their students to highly complicated and expensive devices and systems in a cost-effective way. The use of VR is strong alternative to conventional expensive educational laboratories. 


\section{References}

1. A. Gunasekaran, Agile Manufacturing: A framework for research and development. Int. Journal of Production Economics, vol 62, pp. 87-105, 1999.

2. S. C. Park, A methodology for creating a virtual model for a flexible manufacturing system, Computers in Industry, vol. 56, pp. 734-746, 2005.

3. D. Kotak, S.Wu, M. Fleetwood, H. Tamoto, Agent-based holonic design and operations environment for distributed manufacturing. Computers in Industry, vol. 52, pp. 95-108, 2003.

4. M. Bal, M. Hashemipour, Virtual factory approach for implementation of holonic control in industrial applications: A case study in die-casting industry. Robotics and Computer-Integrated Manufacturing, Vol. 25(3), pp. 570- 580, 2009.

5. S. Cavalieri, M. Macchi, P. Valckenaers, Benchmarking the performance of manufacturing control systems: design principles for a web-based simulated test-bed. J Intell Manufact, vol. 14, pp. 43-58, 2003.

6. Malik V, Fletcher M, Pechoucek M. Holons and agents: recent developments and mutual impacts. In: Proceedings of international conference on multi agent systems and applications, Prague, Czech Republic, LNAI 2322. p. 233-67, 2002.

7. J.S. Smith, S.B. Joshi, and R.G. Qiu, Message-based Part State Graph (MPSG): a formal model for shopfloor control implementation. Int. J. Prod. Res., vol. 41, pp. 1739-1764, 2003.

8. Holonic Manufacturing System (HMS) consortium web site, http:// hms.ifw.uni-hannover.de/. (2000).

9. A. Koestler, The Ghost in the Machine, Arkana, London, 1967.

10. A. Giret, and V. Botti, From requirements to holonic manufacturing system analysis. International journal of production research, vol. 44(18-19), pp. 3917-3928, 2006.

11. A. Giret, V. Botti, Holons and agents. Journal of Intelligent Manufacturing, vol. 15, pp. 645-659, 2004.

12. K. Fischer, M. Schillo, J. Siekmann, Holonic multiagent systems: a foundation for organisation of multiagent systems. Holonic and Multi-Agent Systems for Manufacturing, vol. 2744, pp. 71-80, 2003.

13. P. Blanc, I. Demongodin, P. Castagna, A holonic approach for manufacturing execution system design: An industrial application. Engineering Applications of Artificial Intelligence, vol. 21(3), pp. 315-330, 2008.

14. V. Normand, C. Babski, S. Benford, A. Bullock, S. Carion, N. Farcet, E. Frecon, J. Harvey, N. Kuijpers, N. Magnenat-Thalmann, S. Raupp-Musse, T. Rodden, M. Slater, G. Smith, A. Steed, D. Thalmann, J. Tromp, M. Usoh, G. Van Liempd, and N. Kladias, The COVEN project: exploring applicative, technical and usage dimensions of collaborative virtual environments. Presence: tele-operators and virtual environments, MIT Press, vol. 8(2), 218-236, 1999.

15. H. F. Manesh and D. Schaefer, Virtual Learning Environments for Manufacturing Education and Training, ASEE Computers in Education Journal, Accepted for publication, January-March 2010.

16. J. Gausemeier, J. Fruend, C. Matysczok, AR-Planning Tool - Designing Flexible Manufacturing Systems with Augmented Reality, Proc. 8th Eurographics Workshop on Virtual Environments, Barcelona, Spain, 2002, pp. 19-25.

17. P.R. Moore, J. Pu, H.C. Hg, C.B. Wong, S.K. Chong, X. Chen, J. Adolfsson, P. Olofsgard, J.O. Lundgren, Virtual Engineering: an integrated approach to agile manufacturing machinery design and control, Mechatronics, vol. 13 pp. 1105 - 1121, 2003.

18. G. C. Burdea, Invited Review: The Synergy Between Virtual Reality And Robotics, IEEE Transactions On Robotics And Automation, vol. 15(3), pp. 400-410, 1999.

19. K. Okulicz, Virtual reality-based approach to manufacturing process planning, Int. Journal of Production Research, vol. 42(17), pp. 3493-3504, 2004.

20. S. C. Park, A methodology for creating a virtual model for a flexible manufacturing system, Computers in Industry, vol. 56, pp. 734-746, 2005.

21. P. Banerjee, and D. Zetu, 'Virtual manufacturing', John Wiley and Sons. 2001.

22. S.H. Koh, H. Zhou, H.S. Tan and K.C. Tan, 'Virtual Environments for Manufacturing \& Training (VEMAT)', Distance Learning and the Internet: Human Capacity Development (DLI 2002) Canberra and Sydney Conference. Association of Pacific Rim Universities (APRU). Singapore, 2002.

23. DELMIA-QUEST, www.delmia.com.

24. P. Vrba, JAVA-Based Agent Platform Evaluation, Proceedings of HoloMAS 2003, LNAI 2744, pp,47-58, 2003.

25. J. Kirakowski, The use of questionnaire methods for usability assessment, [Online], http://www.ucc.ie/hfrg/questionnaires/sumi/sumipapp.html, 1994.

26. A. Sutcliffe, and B. Gault, Heuristic evaluation of virtual reality applications, Interact Comput, vol. 16, pp. 831_849, 2004 . 